\title{
Locally adaptive temperature response of vegetative growth in Arabidopsis thaliana
}

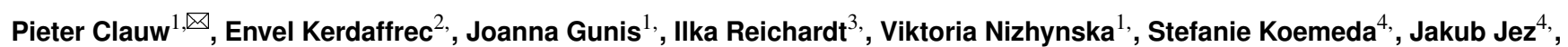 \\ and Magnus Nordborg $1, \bowtie$ \\ ${ }^{1}$ Gregor Mendel Institute of Molecular Plant Biology, Austrian Academy of Sciences, Vienna BioCenter (VBC), 1030 Vienna, Austria \\ ${ }^{2}$ Department of Biology, University of Fribourg, $\mathrm{CH}-1700$ Fribourg, Switzerland \\ ${ }^{3}$ Max Planck Institute of Molecular Cell Biology and Genetics, Dresden, 01307 Dresden, Germany \\ ${ }_{4}^{4}$ Plant Sciences Facility, Vienna BioCenter Core Facilities GmbH (VBCF), 1030 Vienna, Austria
}

\begin{abstract}
We investigated early vegetative growth of natural Arabidop- 45 sis thaliana accessions in cold, non-freezing temperatures, sim- ${ }_{46}$ ilar to temperatures these plants naturally encounter in fall at northern latitudes. We found that accessions from northern latitudes produced larger seedlings than accessions from southern latitudes, partly as a result of larger seed size. However, their subsequent vegetative growth when exposed to colder temperatures was slower. The difference was too large to be explained by ${ }^{5}$ random population differentiation, and is thus suggestive of lo- ${ }^{52}$ cal adaptation, a notion that is further supported by substantial 53 transcriptome and metabolome changes in northern accessions. ${ }^{54}$ We hypothesize that the reduced growth of northern accessions 55 is an adaptive response, and a consequence of reallocating re- 56 sources towards cold acclimation and winter survival.

Correspondence:

pieter.clauw@gmi.oeaw.ac.at

magnus.nordborg@gmi.oeaw.ac.at

\section{Introduction}

Local adaptation studies in Arabidopsis thaliana have found 63 important roles for life history traits such as seed dormancy 64 and flowering time (1). Temperature is a main regulator of 65 these traits and local populations are adapted to their local 66 temperatures (2-4). Also plant growth is affected by tem- 67 perature and previous studies have detected genetic variation 68 underlying rosette sizes and growth rates $(5,6)$ as well as signals of polygenic adaptation (7). How vegetative growth is adapted to local temperatures remains unclear, however. Growth can be seen as the end-sum of a vast number of phys- 70 iological processes. All of these are genetically determined 71 but can also be heavily influenced by environmental condi- 72 tions. Growth is therefore not only genetically a complex 73 trait but also enormously plastic. The most straightforward 74 environmental effect is when conditions are so adverse that 75 growth reaches a physiological limit, making it impossible 76 for the plant to grow any further. This is so-called "passive 77 plasticity" $(8,9)$. Yet, when survival is at stake, it may also 78 be in the interest of the plant to actively inhibit growth upon 79 deteriorating environmental conditions (10) so-called "active 80 plasticity" $(8,9)$. Since vegetative growth ultimately deter- 81 mines photosynthetic surface and thus energy input that can 82 be invested in the next generation, it is in direct trade-off with ${ }_{83}$ survival. Allocation of resources towards either growth or 84 survival is thus an important balance to keep, and plants are 85 expected to be adapted to constantly perceiving and respond- 86 ing to specific environmental changes as cues for upcoming, potentially, adverse conditions.

Cold acclimation is a well-studied example of plants sensing cold temperatures as a cue for upcoming winter and consequently preparing for freezing temperatures. The increased freezing tolerance upon cold acclimations is accomplished by changing membrane composition, producing cryoprotective polypeptides such as $\operatorname{COR} 15 \mathrm{~A}(11,12)$ and accumulating compatible solutes with cryoprotective properties such as raffinose, sucrose and proline (13-15). Main regulators of cold acclimation are CBF1/DREB1b, CBF2/DREB1c and CBF3/DREB1a, three AP2/ERF transcription factors, for which allelic variation in $\mathrm{CBF} 2$ has been linked to natural variation in freezing tolerance (16-18).

Here we investigated the role of growth in adaptation to cold temperatures by comparing vegetative growth of 249 accessions (Figure 1) grown in $16^{\circ} \mathrm{C}$ and $6^{\circ} \mathrm{C}$ for a period of 3 weeks following seedling establishment (Figure 2). Rosette growth of each plant was measured twice a day during temperature treatments, using automated phenotyping. The experiment generated rosette growth estimates at a high temporal resolution in two ecologically realistic temperature conditions in a wide set of accessions, allowing us to look for patterns of local adaptation.

\section{Results}

\section{Estimating plant growth parameters.}

Our experiment yielded dense (two measurements per day) time series growth data for over 7,000 individual plants (249 accessions X 2 treatments X 5 replicate accessions X 3 repeated experiments). These data were used to model plant growth and estimate growth parameters for further analysis. Unlimited growth should be be exponential, but plant growth is known to slow down with increasing size, and therefore a power-law function, $\frac{d M}{d t}=r M^{\beta}$, with $\beta<1$ is typically a better fit than a pure exponential function (for which $\beta=1$ - in the equation, $M$ is the size, $r$ is the growth rate, and $\beta$ is a scaling factor that allows rate of size increase to change with size). Growth according to a power-law function describes early stages of plant growth especially well (20) for the rosette size measurements in this study. To calculate the rosette size from a power-law function at a given time point only three parameters are required: the initial size $(M O)$, 


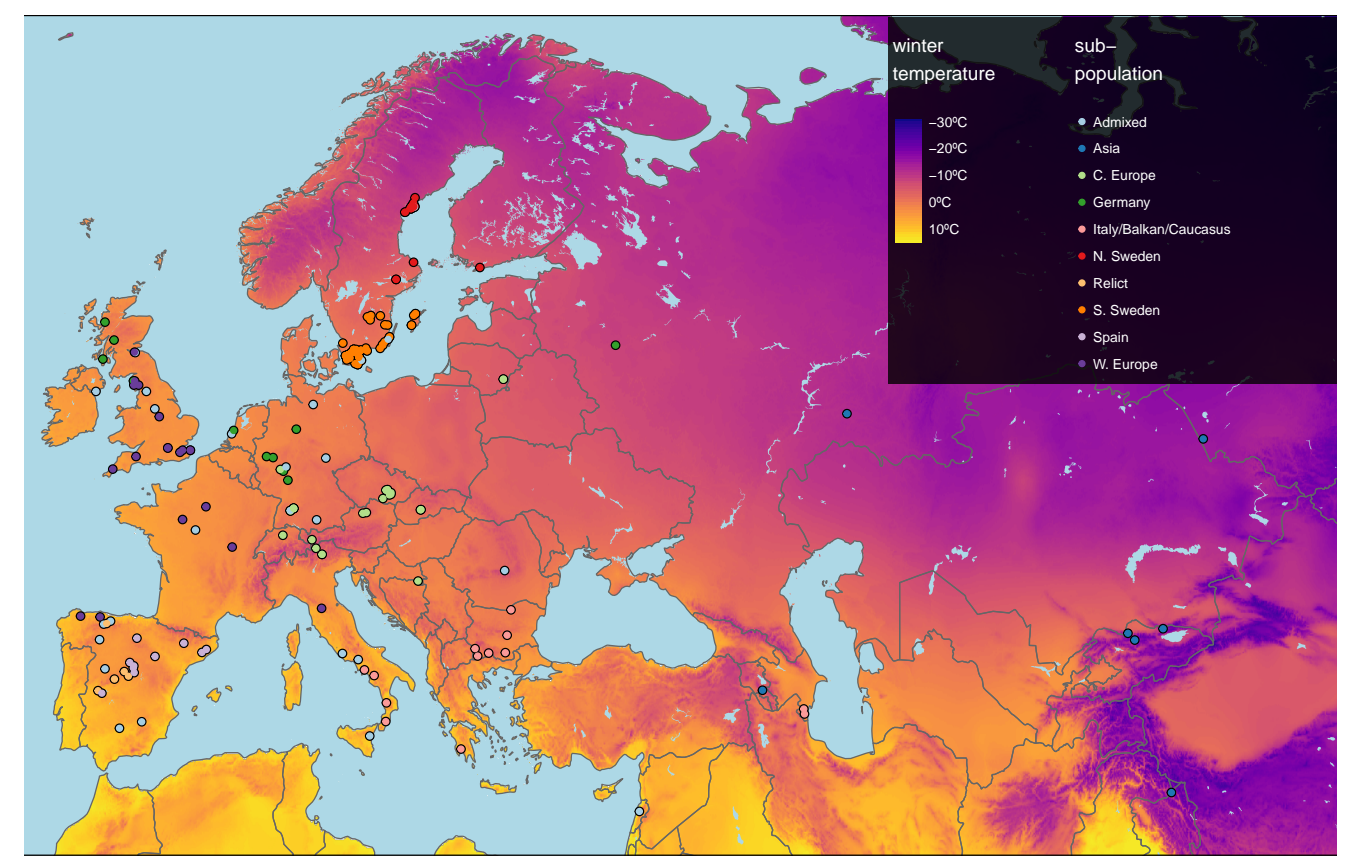

Fig. 1. Geographic origin of the 249 accessions. Map color shows winter temperature (mean temperature of coldest quarter). Accessions are colored according to subpopulation (19).

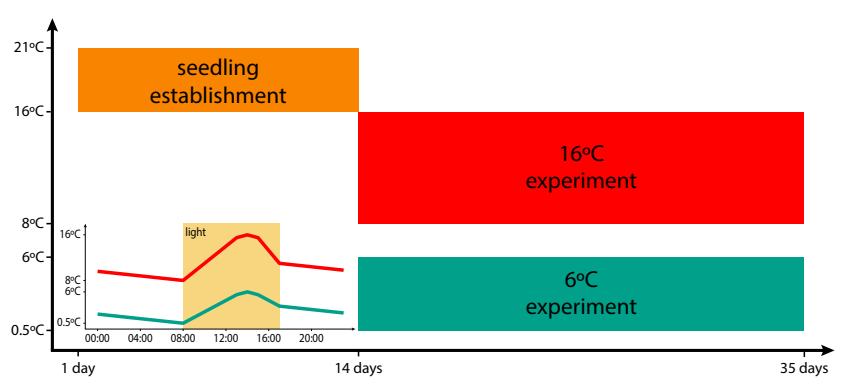

Fig. 2. Timeline of the experiments. Upon vernalisation, seeds germinated and 106 seedlings established over 14 days. After 14 days plants were exposed to either $16^{\circ} \mathrm{C}$ treatment or $6^{\circ} \mathrm{C}$ treatment. Insert shows the 24 hour temperature profile for ${ }^{107}$ the $16^{\circ} \mathrm{C}$ (red) and $6^{\circ} \mathrm{C}$ (green) treatments, with light period indicated in yellow. 108 growth rate $(r)$, and $\beta$. Note that $M 0$ is the rosette size at the ${ }_{110}$ start of the temperature treatment 14 days after stratification ${ }_{111}$ (Figure 2) and is thus not affected by the temperature treat- 112 ment. We used a non-linear mixed model to obtain estimates ${ }_{113}$ for the initial size, growth rates and beta. Accession was ${ }_{114}$ added as fixed effect for initial size and growth rate, temper- ${ }_{115}$ ature and accession $\mathrm{X}$ temperature interactions were added as fixed effects for growth rate only. $\beta$ was considered to be ${ }^{116}$ constant over accessions and temperatures. The "temperature 117 response" of the growth rate was calculated for each acces- 118 sion as the slope between the growth rate at $16^{\circ} \mathrm{C}$ and $6^{\circ} \mathrm{C}$. As 119 expected, all accessions grew faster when it was warmer. The 120 observed phenotypic variation (Figure 3) is to a large extent ${ }^{121}$ explained by genetic variation; broad-sense heritabilities are 122 0.41 for initial size, and 0.57 and 0.32 for growth rate at $16^{\circ} \mathrm{C} 123$ and $6^{\circ} \mathrm{C}$ respectively.

\section{Growth parameters correlate with the environment of 126} origin.

If growth rates are locally adaptive, they may reflect the envi- ${ }_{128}$
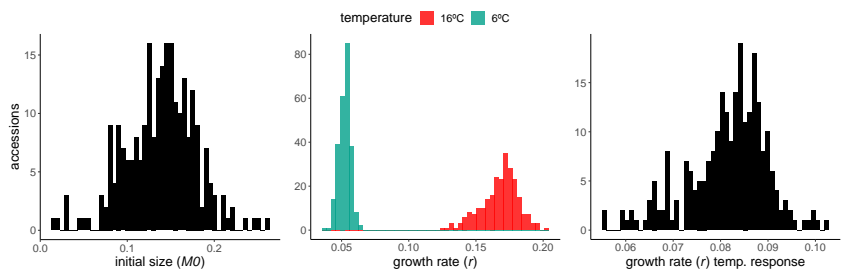

Fig. 3. Variation among accessions of initial size (MO), growth rate $(r)$ and the temperature response of the growth rate.

ronment of origin of each accession. To investigate this, we correlated our estimated growth rates with climate data. The climate variables showing the strongest correlations with the different growth parameters were linked to temperature during winter months (Figure S1), also when correlations were corrected for population structure (Figure S2). In particular, the mean temperature during the coldest quarter (henceforth referred to as "winter temperature") was strongly correlated with our parameter estimates, and we focus on it in what follows.

\section{Initial size.}

Accessions from colder climates generally had higher initial rosette size $(M O), 2$ weeks after germination, than accessions from warmer climates, but then grew more slowly during the temperature experiment - regardless of temperature regime (Figure 4).

At least part of the explanation for this pattern is likely to be differences in seed size between accessions. Using seed size measurements from previous experiments, we found that seed size is positively correlated with initial size, and also with winter temperature (Figure S3), at least for the subset of 123 Swedish accessions. Winter temperature is still significantly associated with initial size when corrected for seed 

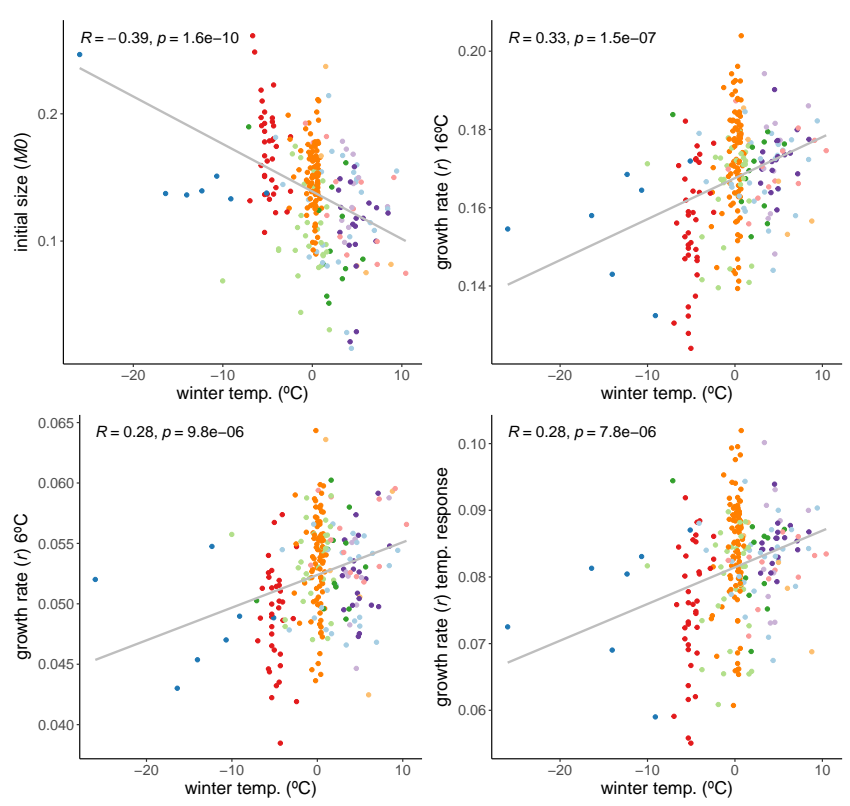

subpopulation

admixed
asia

- relict
south_s spain

Fig. 4. Variation among accessions of initial size $(M 0)$, growth rate $(r)$ and the temperature response of the growth rate.

size by adding it as a random effect. Seed size alone can therefore not explain the geographic pattern we observe for initial size and there must be a role for variation in growth rate during the very initial phases of seedling growth.

\section{Growth rates.}

While the initial sizes correlate negatively with winter temperature, we observed the opposite relation for the growth ${ }^{16}$ rates. Despite being larger initially, accessions from colder ${ }^{162}$ climates grew more slowly during both the $16^{\circ} \mathrm{C}$ and $6^{\circ} \mathrm{C}{ }^{163}$ treatments (Figure 4). Since resources are not limiting, this ${ }^{164}$ suggests that the northern lines are actively inhibiting their ${ }^{165}$ growth, and that growing slower may be beneficial in colder ${ }^{166}$ climates, perhaps in preparation for winter. Accessions from ${ }^{167}$ colder climates were also less sensitive to the temperature ${ }^{168}$ experiment in the sense that the temperature response of the ${ }^{169}$ growth rate increased with winter temperature of origin (Fig- ${ }^{170}$ ure 4).

\section{Cold acclimation response}

In agreement with the variation in growth rates, metabolite measurements taken at the final day of our experiment showed clear differences between accessions from cold and warm regions, and many of these differences involved ${ }^{176}$ metabolites with a known role in cold acclimation (21). Since 177 the transcriptomic component of cold acclimation is well ${ }_{178}$ studied, we analyzed the expression profiles of 251 known 179 cold acclimation genes in 8 accessions chosen to be represen- 180 tative in terms of their growth and metabolome profiles (Fig- 181 ure S4). The selected genes are known to be differentially 182 expressed upon exposure to cold, and their expression is un- 183 der control of at least one of the known transcription factors 184 regulating cold acclimation: CBF1, CBF2, CBF3, HSFC1 185 (22) or ZAT12 (23). In our experiment, expression of these 186

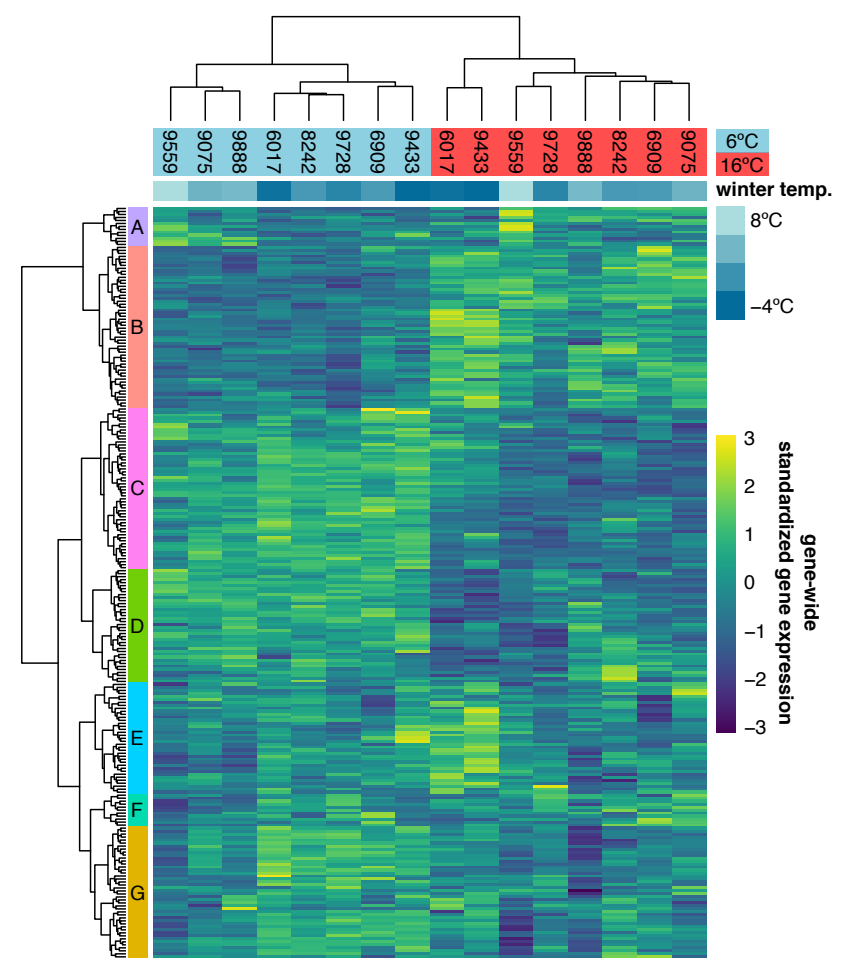

Fig. 5. Expression of known cold acclimation genes. Expression is shown as the gene-wide z-scores of the normalized counts. The z-scores allow for grouping genes with a similar expression behavior over the different accessions in both temperatures. The top bar indicates winter temperature $\left({ }^{\circ} \mathrm{C}\right)$ for each accession's origin. Both dendrograms along $y$-axis and $x$-axis respectively show hierarchical clustering of genes, and of accessions in both temperatures.

genes is likewise more affected by temperature than expected by chance (Figure $5 ; \chi^{2}$-test: p-value $<0.001$ ), and separates the two accessions from the coldest region (northern Sweden) from the rest in the $16^{\circ} \mathrm{C}$ treatment, and the three accessions from the warmest regions (Spain and Azerbaijan) from the rest in the $6^{\circ} \mathrm{C}$ treatment. Expression of different subsets of the selected cold-acclimation genes show clear correlations with winter temperature of origin (Figure S5). In particular, the genes that were previously found to be up-regulated upon cold exposure showed higher expression in accessions from cold climates (Figure S6). Since the expression of these cold acclimation genes is linked to the strength of cold acclimation, these accessions likely differ in their ability to cope with freezing temperatures upon cold treatment.

\section{Growth is polygenic and shows signs of local adaptation}

We used genome-wide association to investigate the genetic architecture underlying variation for the different growth parameters (Figure S7). The most significant association was found for overall growth rate in $16^{\circ} \mathrm{C}$ (Figure 6). Inflated significance levels after correcting for population structure are consistent with what we would expect from a polygenic trait (Figure 6) and were also observed for the other traits, except for growth rate in $6^{\circ} \mathrm{C}$ (Figure S7). Plausible candidates within $10 \mathrm{~kb}$ of the most significant SNP (chr5:23,334,281) include CIPK21 and MYB36. CIPK21 encodes a CBL- 
interacting protein kinase that is upregulated in cold condi- 243 tions and is involved in the salt and osmotic stress response ${ }_{244}$ (24). MYB36 is a key regulator of root endodermal differ- 245 entiation (25). Slightly more distant, 22kb away, is COL5, a 246 transcription factor that is part of the gene network that is reg- 247 ulated by AN3, a regulator of cell proliferation in leaf growth ${ }_{248}$ (26).

\section{9} To test for potential polygenic adaptation, we compared the 250 phenotypic divergence to the expected neutral genome-wide 251 genetic divergence. This can be done using a so-called ${ }_{252}$ $Q_{S T}-F_{S T}$ test (27-29), however this test is not well suited ${ }_{253}$ for species with complex population structure, and so we 254 used a variation that was designed to detect adaptive differ- 255 entiation for traits measured in structured GWAS panels (30). 256 Instead of looking at divergences between predefined popu- 257 lations, this method uses principal components (PCs) of the 258 genetic relatedness matrix as axes of potential adaptive dif- 259 ferentiation. Adaptive differentiation is then detected as a 260 correlation between the focal phenotype and any of these re- ${ }_{261}$ latedness PCs that is significantly different than expected un- ${ }_{262}$ der neutrality. Adaptive differentiation was detected for initial size and for ${ }^{263}$ growth rate in $16^{\circ} \mathrm{C}$ and its temperature response. Both traits show adaptive differentiation along different genetic axes ${ }_{260}$ (Figure 7). Initial size shows significant adaptive differen- ${ }_{267}$ tiation along PC6 (p-value $<0.05$ ), whereas growth rate in ${ }_{268}$ $16^{\circ} \mathrm{C}$ and its temperature response showed significant adap- ${ }_{269}$ tive differentiation along PC5 ( $\mathrm{p}$-values $<0.05$ ). The adaptive ${ }_{270}$ differentiation for initial size along PC6 seems to stem from ${ }_{271}$ higher initial sizes in Swedish accessions, compared to cen- ${ }_{272}$ tral European accessions. The adaptive differentiation along 273 PC5 seems to be driven by the lower growth rate temperature ${ }_{274}$ responses in Asian and Northern Swedish accessions in con- ${ }_{275}$ trast to higher growth rates in a subset of southern Swedish 276 accessions. The accessions in our set that come from North- ${ }_{277}$ ern Sweden and Asia hail from the coldest climates. Thus ${ }_{278}$ these results suggest adaptive differentiation driven by adap- ${ }_{279}$ tation to cold winters.

\section{Discussion}

This study explores the natural variation of rosette growth ${ }^{283}$ in non-freezing temperatures. Despite high plasticity, we de- 284 tect genetic variation for the different growth parameters, and ${ }^{285}$ environmental correlations suggest local adaptation. GWAS ${ }^{286}$ analyses reveal, not surprisingly, a polygenic trait architec- 287 ture. Indeed, across the genome we detect adaptive differen- ${ }^{288}$ tiation for certain growth parameters. We speculated that the ${ }^{289}$ slower growth measured in accessions from colder climates 290 reflect relocation of resources from growth towards cold ac- 291 climation. Both metabolome and gene expression data are ${ }^{292}$ consistent with accessions from colder climates preparing for ${ }^{293}$ a harsh winter. In our temperature experiment, we see that the ${ }^{294}$ growth of northern lines is affected less than southern lines by 295 switching from $16^{\circ} \mathrm{C}$ to $6^{\circ} \mathrm{C}$.

Our conclusion that slower growth is likely adaptive in pop- ${ }^{297}$ ulations facing fiercer winters is in line with recent results of 298 Wieters et al. (7), who concluded that the reduced growth 299 in Northern lines was adaptive and not a consequence of an accumulation of deleterious mutations at the species border. If slower growth were indeed a consequence of accumulated deleterious mutations we would expect to see slower growth also during the initial seedling establishment. On the contrary, we saw a fast seedling establishment for accessions from colder regions. We speculate that the fast seedling establishment is a potential adaptation for short growth seasons, which often coincide with colder climates (high latitude or high altitude). This fast seedling establishment seems to be partly supported by larger seeds. These larger seeds may provide more nutrients to initiate faster seedling establishment, while this is of less importance in warmer climates with longer growth seasons. Further work is needed to disentangle initial growth from seed size effects and confirm that there is a causal relationship between seed size and fast seedling establishment, whether this is due to seed nutrient storage, and whether it is adaptive.

The adaptation of growth to local climates is likely to be influenced by a trade-off with cold acclimation. General growth-survival trade-offs have long been observed and are described in general ecological strategy schemes such as Grime's C-S-R triangle (31) and the leaf-height-seed scheme (32). Specific trade-offs between growth and cold/frost survival were observed for wheat $(33,34)$, alfalfa (35), Dactylis glomerata (36), and multiple tree species (37-40). Here we observed higher expression of genes involved in cold acclimation in accessions from colder regions. Even though this is based on a limited set of 8 accessions, metabolome measurements in all 249 accessions lead to the same conclusion. Metabolites involved in cold acclimation such as raffinose, sucrose and proline were found in higher concentrations in accessions from colder climates (21). We believe that accessions from colder environments are relocating more energy and resources from growth towards preparations for upcoming freezing temperatures. This likely results in stronger cold acclimation and consequently increased freezing tolerance in the accessions from colder regions. Indeed, accessions originating from colder environments show increased freezing tolerance upon cold acclimation (41-44).

There is strong evidence from QTL mapping that genetic variation in the $C B F 2$ gene is one of the drivers for adaptation to freezing stress $(16,45)$. Here we looked at growth phenotypes and did not detect associations with the CBF loci. In the transcriptome analysis we did pick-up a role for $\mathrm{CBF}$ and other known cold-acclimation genes. The most significant locus detected in our GWAS analysis (for growth rate in $16^{\circ} \mathrm{C}$ ) lies in the vicinity of $C O L 5$, a gene that is part of a leaf growth regulatory network (26) and whose expression is induced by both cold treatment and $C B F 1, C B F 2$ and $C B F 3$ overexpression (22). In our transcriptome data, the COL5 gene was found in cluster $\mathrm{D}$, showing higher expression in accessions coming from warmer regions. It is however unclear what its exact regulatory role in growth in cold conditions might be.

In summary, we detected adaptive differentiation for growth between accessions from warm and cold climates. Our tran- 

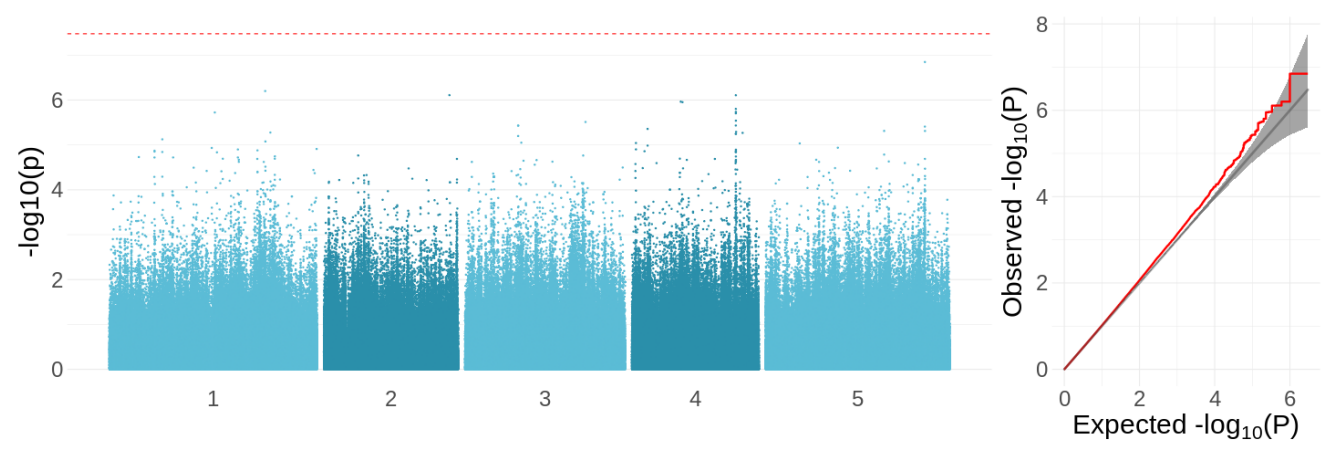

Fig. 6. GWAS results for the growth rate in $16^{\circ} \mathrm{C}$. (A) Manhattan plot showing the significance of the association between the phenotype and each of the tested SNPs (MAF $>10 \%$ ). The Bonferroni-corrected threshold is shown with a dashed red line. (B) QQ-plot showing the relation between observed and expected -log10(p-value) distributions. Red line shows the observed relationship. The gray line and band show the expected relationship under the null hypothesis of no differentiation between both distributions.

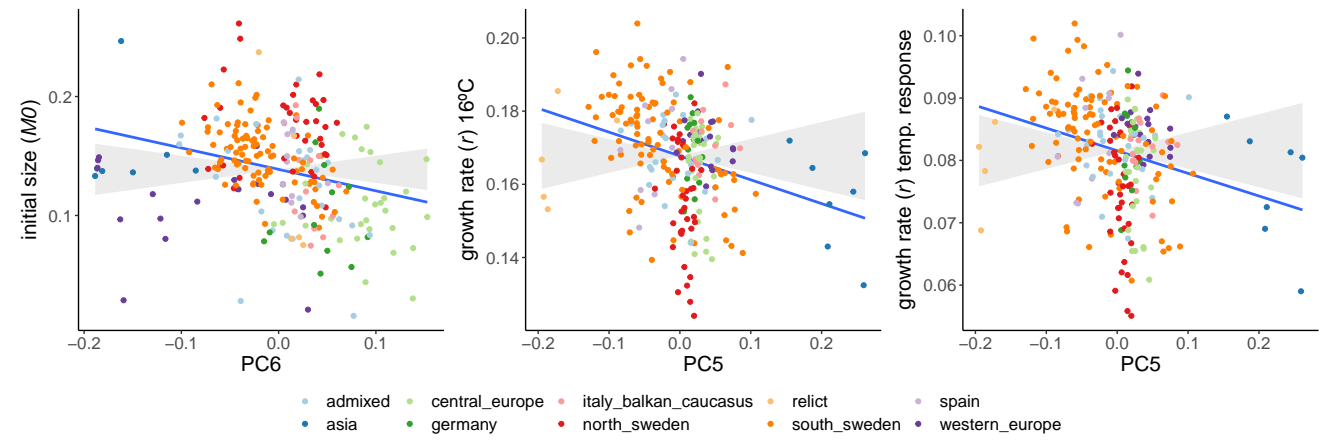

Fig. 7. Adaptive differentiation of initial size, growth rate at $16^{\circ} \mathrm{C}$, and the temperature response of growth rate along different axes of genetic differentiation. Accessions are coloured according to their respective admixture groups, as specified in (19). The gray ribbon represents the expected correlation between phenotype and axis of genetic differentiation under neutrality. The blue line represents the observed correlation between phenotype and axis of genetic differentiation.

scriptome data and previous metabolome data suggest that ${ }_{328}$ resources are relocated from growth to cold acclimation in ${ }_{329}$ accessions from colder regions. This allows these accessions 330 to be fully prepared for the coming of winter.

\section{Materials and Methods}

\section{Plant growth and phenotyping.}

Seeds of 249 natural accessions (Suppl. Data 1) of Arabidop- ${ }^{335}$ sis thaliana described in the 1001 genomes project (19) were ${ }^{336}$ sown on sieved $(6 \mathrm{~mm})$ substrate (Einheitserde ED63). Pots ${ }^{337}$ were filled with $71.5 \mathrm{~g} \pm 1.5 \mathrm{~g}$ of soil to assure homogenous packing. The prepared pots were all covered with blue mats (46) to enable a robust performance of the high-throughput image analysis algorithm. Seeds were stratified (4 days at ${ }_{341}$ $4^{\circ} \mathrm{C}$ in darkness) after which they germinated and left to grow ${ }^{342}$ for 2 weeks at $21^{\circ} \mathrm{C}$ (relative humidity: 55\%; light intensity: ${ }_{343}$ $160 \mu \mathrm{mol} \mathrm{m} \mathrm{m}^{-2} \mathrm{~s}^{-1} ; 14 \mathrm{~h}$ light). The temperature treatments were started by transferring the seedlings to either $6{ }^{\circ} \mathrm{C}$ or ${ }_{345}$ $16{ }^{\circ} \mathrm{C}$. To simulate natural conditions temperatures fluctuated diurnally between $16-21^{\circ} \mathrm{C}, 0.5-6{ }^{\circ} \mathrm{C}$ and $8-16{ }^{\circ} \mathrm{C}$ for ${ }^{347}$ the $21{ }^{\circ} \mathrm{C}$ initial growth conditions and the $6{ }^{\circ} \mathrm{C}$ and $16^{\circ} \mathrm{C}_{348}^{347}$ treatments, respectively (Figure 2). Light intensity was kept constant at $160 \mu \mathrm{mol} \mathrm{m} \mathrm{m}^{-2} \mathrm{~s}^{-1}$ throughout the experiment. Relative humidity was set at $55 \%$ but in colder temperatures it rose uncontrollably to maximum $95 \%$. Daylength was $9 \mathrm{~h}$ during the $16^{\circ} \mathrm{C}$ and $6^{\circ} \mathrm{C}$ treatments. Each temperature treatment was repeated in three independent experiments. Five replicate plants were grown for every genotype per experiment. Plants were randomly distributed across the growth chamber with an independent randomisation pattern for each experiment. During the temperature treatments (14 DAS 35 DAS), plants were photographed twice a day (1 hour after/before lights switched on/off), using an RGB camera (IDS uEye UI-548xRE-C; 5MP) mounted to a robotic arm. At 35 DAS, whole rosettes were harvested, immediately frozen in liquid nitrogen and stored at $-80^{\circ} \mathrm{C}$ until further analysis. Rosette areas were extracted from the plant images using Lemnatec OS (LemnaTec GmbH, Aachen, Germany) software.

\section{Non-linear modeling.}

Non-linear modeling was used to describe plant growth in a minimum number of parameters. In a first step we constructed a simple non-linear model with plant size being explained by either the exponential (equation 1) or the powerlaw function (equation 2), with individual plant as a random effect for each of the model parameters; $M O, r$ and. With being only present in the power-law model. Models were constructed using the nlsList and nlme functions from the nlme package for R. Exponential and power-law SelfStart functions were used from Paine et al. (20). Based on Akaike Information criterion and likelihood ratio test generated by the anova function, we decided to use the power-law model for further analyses.

$$
\begin{aligned}
\frac{d M}{d t} & =r M \\
M_{t} & =M_{0} e^{r t}
\end{aligned}
$$




$$
\begin{aligned}
\frac{d M}{d t} & =r M^{\beta} \\
M_{t} & =\left(M_{0}^{1-\beta}+r t(1-\beta)\right)^{1 / 1-\beta}
\end{aligned}
$$

In a second step, we constructed a model with fixed effects ${ }_{408}^{407}$ for the different power-law parameters. For initial size $(M O)_{409}$ we added accession as fixed effect. Temperature treatment ${ }_{410}$ only started from the initial time point onwards, and thus ${ }_{411}$ could not have an effect on the initial plant size. The growth rate, on the other hand, should be affected by temperature, ${ }_{413}$ therefore we included accession, temperature and their inter- ${ }_{414}$ action as fixed effects for growth rate $(r)$. No fixed effects ${ }_{415}$ were added for $\beta$ The idea here is that is an adjustment factor for decreasing growth rates (when $\beta<1$ ) with increasing plant sizes, which is general for plant growth, or at least ${ }_{416}$ for our data in this case. Individuals, nested with experi- ${ }_{417}$ ment, were added as random effects for each of the model ${ }_{418}$ parameters. The correlation structure intrinsic to measuring ${ }_{419}$ the same individuals over time was accounted for by adding ${ }_{420}$ the first order continuous autoregressive correlation structure ${ }_{42}$ (corCAR1). The estimated fixed effects of this model were ${ }_{422}$ then used to obtain initial size estimates for each accession ${ }_{423}$ and growth rate estimates for each accession in both temper- ${ }_{424}$ atures. These estimates were used for all further analyses. ${ }_{425}$ Exceptions to this are the broad-sense heritabilities, which ${ }_{426}$ were based on initial size and growth rate estimates that were ${ }_{427}$ obtained by including random effects, in order to get esti- ${ }_{428}$ mates for each individual plant.

\section{Climate correlations.}

The different phenotypes were correlated with each ${ }_{432}$ of the different (bio)climate variables downloaded from ${ }_{433}$ www.worldclim.org (47). Correlations were calculated as ${ }_{434}$ Pearson's correlations using the cor function in R (48). Popu- ${ }_{435}$ lation structure may confound the correlation between pheno- ${ }_{436}$ type and climate. Therefore we included a population struc- ${ }_{437}$ ture corrected phenotype-climate correlation (Figure S2). $\mathrm{To}_{438}$ this end we used a mixed-effects model as implemented in ${ }_{439}$ the lmekin function from the coxme package with phenotype ${ }_{440}$ as dependent variable, climate variable as fixed effects and ${ }_{441}$ the kinship matrix as random effect. Phenotype and climate ${ }_{442}$ variables were standardized, so that regression coefficients ${ }_{443}$ were comparable to correlation coefficients. Even though the strength and significance of the correlations weaken upon population structure correction, the growth parameters still ${ }_{444}$ demonstrate the same pattern of most strongly correlating ${ }_{445}$ with winter temperatures.

\section{Seed size correlations.}

$$
446
$$

We used the seeds produced by (49) and limited our mea- 449 surements to the set of 123 Swedish accessions that over-450 lapped with our growth dataset. After seed stratification for ${ }^{451}$ four days at $4^{\circ} \mathrm{C}$ in darkness, mother plants were grown for 8452 weeks at $4^{\circ} \mathrm{C}$ under long-day conditions (16h light; 8h dark) ${ }_{453}$ to ensure proper vernalization. Temperature was raised to 454 $21^{\circ} \mathrm{C}$ (light) and $16^{\circ} \mathrm{C}$ (dark) for flowering and seed ripen- 455 ing. Seeds were kept in darkness at $16^{\circ} \mathrm{C}$ and $30 \%$ relative humidity, from the harvest until seed size measurements. For each genotype three replicates were pooled and about 200-300 seeds were sprinkled on 12 x $12 \mathrm{~cm}$ square, transparent Petri dishes. Image acquisition was performed as described in (50) by scanning dishes on a cluster of eight Epson V600 scanners. The resulting 1200 dpi tiff images were analyzed in the ImageJ software (2.1.0/1.53c). Images were converted to 8-bit binary images and thresholded with the setAutoThreshold("Defaultdark") command, and seed area was measured in squared mm by running the Analyse Particles command (inclusion parameters: size $=0.04-0.25$ circularity $=0.70-1.00)$. All scripts used for image processing are available at https://github.com/vevel/seed_size.

\section{Transcriptome profiling.}

35 days after stratification, rosette tissue of all plants were harvested and flash frozen in liquid nitrogen. Random samples in each replicate and temperature were taken for 8 accessions to profile the transcriptome with RNA-sequencing. Total RNA was extracted using the KingFisher Duo Prime System (Thermo Fisher Scientific) together with a high performance RNA bead isolation kit (Molecular Biology Service, VBC Core Facilities, Vienna). To determine the quantity of RNA samples we used Fluorometer Qubit 4 (Invitrogen) and Qubit RNA BR Kit (Invitrogen). For each sample, $1 \mu \mathrm{g}$ of total RNA was treated with the poly(A) RNA Selection Kit (Lexogen) and eluted in $12 \mu \mathrm{l}$ of Nuclease-Free Water. Libraries were prepared according to the manufacturer's protocol in NEBNext Ultra II Directional RNA Library Prep Kit (New England BioLabs) and individually indexed with NEBNext Multiplex Oligos for Illumina (New England BioLabs). The quantity and quality of each amplified library were analyzed by using Fragment Analyzer (Agilent) and HS NGS Fragment Kit (Agilent). Libraries were sequenced with an Illumina HiSeq2500 in paired-end mode with read-length of $125 \mathrm{bp}$. Sequencing was performed by the Next Generation Sequencing Facility at Vienna BioCenter Core Facilities (VBCF), member of the Vienna BioCenter (VBC), Austria. Gene expression was quantified by using quasi-mapping in salmon, version 1.2.1 (51). The salmon indices were built separately for each accession, as we incorporated the SNP variation from the (19) into the reference transcriptome.

\section{Broad-sense heritabilities.}

Broad-sense heritability $\left(\mathrm{H}^{2}\right)$ for initial size was calculated using the estimates for each individual plant, over all experiments. $H^{2}$ for growth rate was calculated separately for each temperature, again using estimates for each individual plant. A mixed model with genotype as random effect and experiment as fixed effects was used to estimate the variance explained by genotype $\left(V_{g}\right)$. Residual variance was taken as an environmental variance $\left(V_{e}\right) . H^{2}$ was then calculated as the ratio between $V_{g}$ and the sum of $V_{g}$ and $V_{e}$. The mixed model was constructed with the lmer function in the lme4 $\mathrm{R}$ package. 
bioRxiv preprint doi: https://doi.org/10.1101/2022.02.15.480488; this version posted February 17, 2022. The copyright holder for this preprint (which was not certified by peer review) is the author/funder, who has granted bioRxiv a license to display the preprint in perpetuity. It is made available under aCC-BY 4.0 International license.

\section{Genome-wide association mapping.}

457 (52).

\section{Testing for adaptive differentiation.}

\section{ACKNOWLEDGEMENTS} valuable comments on the manuscript.

\section{Supplementary Information} https://github.com/vevel/seed_size. odo. 6076948

\section{Bibliography} Exp. Bot., 70(4):1141-1151, February 2019. Science, 296(5566):285-289, April 2002. (4):e1007954, April 2019.
Genome-wide association mapping was done for each of the ${ }^{51}$ growth parameters, in both temperatures and also the temper- 520 ature response for the growth rate. We used a mixed model ${ }_{52}^{521}$ with phenotype as dependent variable, genotype as fixed ef- ${ }_{523}^{522}$ fect and genetic relatedness as random factor. Genotypes ${ }_{525}^{524}$ non-imputed SNPs obtained from the 1001 genomes consor- ${ }_{526}^{525}$ tium (19). This model was run in GEMMA, version $0.98 .3_{528}^{527}$

Adaptive differentiation was tested with the method de- ${ }^{533}$ scribed by Josephs et al. (30) and the accompanying $\mathrm{R}_{535}^{534}$ package quaint (https://github.com/emjosephs/quaint). Kin- ${ }_{537}^{536}$ ship matrix was calculated using the make_k function in the ${ }_{538}$ quaint package in R. Genetic principal components were then ${ }_{540}^{539}$ calculated from the eigen decomposition of the kinship ma- ${ }^{541}$ trix. Adaptive differentiation of each phenotype along the ${ }_{543}^{542}$ first 10 principal components was tested with the calcQpc ${ }_{544}^{543}$ function in the quaint R package. Principal components $11-{ }_{546}^{545}$ 248 were used to build the expected phenotypic differentia- ${ }^{547}$ tion under neutrality.

dhe Nordborg group for their help setting up and harvesting these experiments. Thanks also to Daniele Filiault for her ${ }_{553}$

Scripts can be found

https://github.com/picla/growth_16C_6C/.

found

for seedsize analysis can be found in ${ }_{563}^{562}$

Supplemental dataset 1. List of all 249 accessions. Supple- ${ }_{566}^{565}$ mental dataset 2. Cold acclimation genes and their expres- ${ }^{567}$ sion cluster membership as shown in Figure 5. All RNA-sequecing were uploaded to SRA under ${ }^{570}$ http://www.ncbi.nlm.nih.gov/bioproject/807069 All gen- ${ }^{572}$ erated phenotyping data are filed under 10.5281/zen-573 and Juliette De Meaux. Linking genes with ecological strategies in arabidopsis thaliana. J. ${ }^{581}$

2. Alejandra Martínez-Berdeja, Michelle C Stitzer, Mark A Taylor, Miki Okada, Exequiel 583 Ezcurra, Daniel E Runcie, and Johanna Schmitt. Functional variants of DOG1 control seed 584 chilling responses and variation in seasonal life-history strategies in arabidopsis thaliana. 585 Proc. Natl. Acad. Sci. U. S. A., 117(5):2526-2534, February 2020.

3. Gordon G Simpson and Caroline Dean. Arabidopsis, the rosetta stone of flowering time? 587

4. Jo Hepworth, Rea L Antoniou-Kourounioti, Rebecca H Bloomer, Catja Selga, Kristina 589 Berggren, Deborah Cox, Barley R Collier Harris, Judith A Irwin, Svante Holm, Torbjörn 590 Säll, Martin Howard, and Caroline Dean. Absence of warmth permits epigenetic memory of 591 winter in arabidopsis. Nat. Commun., 9(1):639, February 2018.

5. Johanna A Bac-Molenaar, Dick Vreugdenhil, Christine Granier, and Joost J B Keurentjes. 593 Genome-wide association mapping of growth dynamics detects time-specific and general 594 quantitative trait loci. J. Exp. Bot., 66(18):5567-5580, September 2015.

6. Elodie Marchadier, Mathieu Hanemian, Sébastien Tisné, Liên Bach, Christos Bazakos, 596 Elodie Gilbault, Parham Haddadi, Laetitia Virlouvet, and Olivier Loudet. The complex ge- 597 netic architecture of shoot growth natural variation in arabidopsis thaliana. PLOS Genet., 15598

7. Benedict Wieters, Kim A Steige, Fei He, Evan M Koch, Sebastián E Ramos-Onsins, Hongya 600 $\mathrm{Gu}$, Ya-Long Guo, Shamil Sunyaev, and Juliette de Meaux. Polygenic adaptation of rosette 601 growth in arabidopsis thaliana. PLOS Genet., 17(1):e1008748, January 2021.
8. A Forsman. Rethinking phenotypic plasticity and its consequences for individuals, populations and species. Heredity, 115(4):276-284, October 2015.

9. Mark Van Kleunen and Markus Fischer. Constraints on the evolution of adaptive phenotypic plasticity in plants, 2005.

10. Hannes Claeys and Dirk Inzé. The agony of choice: how plants balance growth and survival under water-limiting conditions. Plant Physiol., 162(4):1768-1779, August 2013.

11. N N Artus, M Uemura, P L Steponkus, S J Gilmour, C Lin, and M F Thomashow. Constitutive expression of the cold-regulated arabidopsis thaliana COR15a gene affects both chloroplast and protoplast freezing tolerance. Proc. Natl. Acad. Sci. U. S. A., 93(23):13404-13409, November 1996.

12. P L Steponkus, M Uemura, R A Joseph, S J Gilmour, and M F Thomashow. Mode of action of the COR15a gene on the freezing tolerance of arabidopsis thaliana. Proc. Natl. Acad. Sci. U. S. A., 95(24):14570-14575, November 1998.

13. T Nanjo, M Kobayashi, Y Yoshiba, Y Kakubari, K Yamaguchi-Shinozaki, and K Shinozaki. Antisense suppression of proline degradation improves tolerance to freezing and salinity in arabidopsis thaliana. FEBS Lett., 461(3):205-210, November 1999.

14. Sarah J Gilmour, Audrey M Sebolt, Maite P Salazar, John D Everard, and Michael F Thomashow. Overexpression of the arabidopsis CBF3Transcriptional activator mimics multiple biochemical changes associated with cold acclimation. Plant Physiol., 124(4):18541865, December 2000.

15. Teruaki Taji, Chieko Ohsumi, Satoshi luchi, Motoaki Seki, Mie Kasuga, Masatomo Kobayashi, Kazuko Yamaguchi-Shinozaki, and Kazuo Shinozaki. Important roles of droughtand cold-inducible genes for galactinol synthase in stress tolerance in arabidopsis thaliana. Plant J., 29(4):417-426, February 2002.

16. C G Oakley, J Ågren, R A Atchison, and others. QTL mapping of freezing tolerance: links to fitness and adaptive trade-offs. Molecular, 2014.

17. Sunchung Park, Sarah J Gilmour, Rebecca Grumet, and Michael F Thomashow. CBFdependent and CBF-independent regulatory pathways contribute to the differences in freezing tolerance and cold-regulated gene expression of two arabidopsis ecotypes locally adapted to sites in sweden and italy. PLoS One, 13(12):e0207723, December 2018

18. Carlos Alonso-Blanco, Concepción Gomez-Mena, Francisco Llorente, Maarten Koornneef, Julio Salinas, and José M Martínez-Zapater. Genetic and molecular analyses of natural variation indicate $\mathrm{CBF} 2$ as a candidate gene for underlying a freezing tolerance quantitative trait locus in arabidopsis. Plant Physiol., 139(3):1304-1312, November 2005.

19. 1001 Genomes Consortium. 1,135 genomes reveal the global pattern of polymorphism in arabidopsis thaliana. Cell, 166(2):481-491, June 2016.

20. C E Timothy Paine, Toby R Marthews, Deborah R Vogt, Drew Purves, Mark Rees, Andy Hector, and Lindsay A Turnbull. How to fit nonlinear plant growth models and calculate growth rates: an update for ecologists. Methods Ecol. Evol., 3(2):245-256, April 2012.

21. Jakob Weiszmann, Pieter Clauw, Joanna Jagoda, Ilka Reichardt-Gomez, Stefanie Koemeda, Jakub Jez, Magnus Nordborg, Dirk Walther, Thomas Nägele, and Wolfram Weckwerth. Plasticity of the primary metabolome in 241 cold grown arabidopsis thaliana accessions and its relation to natural habitat temperature. preprint on BioRxiv, September 2020.

22. Sunchung Park, Chin-Mei Lee, Colleen J Doherty, Sarah J Gilmour, Yongsig Kim, and Michael $\mathrm{F}$ Thomashow. Regulation of the arabidopsis CBF regulon by a complex lowtemperature regulatory network, 2015.

23. Jonathan T Vogel, Daniel G Zarka, Heather A Van Buskirk, Sarah G Fowler, and Michael F Thomashow. Roles of the CBF2 and ZAT12 transcription factors in configuring the low temperature transcriptome of arabidopsis. Plant J., 41(2):195-211, January 2005.

24. Girdhar K Pandey, Poonam Kanwar, Amarjeet Singh, Leonie Steinhorst, Amita Pandey, Akhlilesh K Yadav, Indu Tokas, Sibaji K Sanyal, Beom-Gi Kim, Sung-Chul Lee, Yong-Hwa Cheong, Jörg Kudla, and Sheng Luan. Calcineurin B-Like Protein-Interacting protein kinase CIPK21 regulates osmotic and salt stress responses in arabidopsis. Plant Physiol., 169(1): 780-792, September 2015.

25. Louisa M Liberman, Erin E Sparks, Miguel A Moreno-Risueno, Jalean J Petricka, and Philip N Benfey. MYB36 regulates the transition from proliferation to differentiation in the arabidopsis root. Proc. Natl. Acad. Sci. U. S. A., 112(39):12099-12104, September 2015.

26. Liesbeth Vercruyssen, Aurine Verkest, Nathalie Gonzalez, Ken S Heyndrickx, Dominique Eeckhout, Soon-Ki Han, Teddy Jégu, Rafal Archacki, Jelle Van Leene, Megan Andriankaja, Stefanie De Bodt, Thomas Abeel, Frederik Coppens, Stijn Dhondt, Liesbeth De Milde, Mattias Vermeersch, Katrien Maleux, Kris Gevaert, Andrzej Jerzmanowski, Moussa Benhamed, Doris Wagner, Klaas Vandepoele, Geert De Jaeger, and Dirk Inzé. ANGUSTIFOLIA3 binds to SWI/SNF chromatin remodeling complexes to regulate transcription during arabidopsis leaf development. Plant Cell, 26(1):210-229, January 2014.

27. T Prout and J S Barker. F statistics in drosophila buzzatii: selection, population size and inbreeding. Genetics, 134(1):369-375, May 1993.

28. Michael C Whitlock. Evolutionary inference from QST. Mol. Ecol., 17(8):1885-1896, April 2008.

29. K Spitze. Population structure in daphnia obtusa: quantitative genetic and allozymic variation. Genetics, 135(2):367-374, October 1993.

30. Emily B Josephs, Jeremy J Berg, Jeffrey Ross-Ibarra, and Graham Coop. Detecting adaptive differentiation in structured populations with genomic data and common gardens. Genetics, 211(3):989-1004, March 2019.

31. J P Grime. Primary strategies in plants. Transactions of the Botanical Society of Edinburgh, 43(2):151-160, November 1979.

32. Mark Westoby. A leaf-height-seed (LHS) plant ecology strategy scheme. Plant Soil, 199(2): 213-227, February 1998.

33. H K Hayes and O S Aamodt. Inheritance of winter hardiness and growth habit in crosses of marquis with minhardi and minturki wheats. J. Agric. Res., 35(223):236, 1927.

34. Karl S Quisenberry. Inheritance of Winter Hardiness, Growth Habit, and Stem-rust Reaction in Crosses Between Minhardi Winter and H-44 Spring Wheats. U.S. Department of Agriculture, 1931.

35. Yves Castonguay, Serge Laberge, E Charles Brummer, and Jeffrey J Volenec. Alfalfa winter hardiness: A research retrospective and integrated perspective*. In Advances in Agronomy, volume 90, pages 203-265. Academic Press, January 2006.

36. Pauline Bristiel, Lauren Gillespie, Liv Østrem, Jennifer Balachowski, Cyrille Violle, and Flo- 
bioRxiv preprint doi: https://doi.org/10.1101/2022.02.15.480488; this version posted February 17,2022 . The copyright holder for this preprint (which was not certified by peer review) is the author/funder, who has granted bioRxiv a license to display the preprint in perpetuity. It is made available under aCC-BY 4.0 International license.

rence Volaire. Experimental evaluation of the robustness of the growth-stress tolerance trade-off within the perennial grass dactylis glomerata. Funct. Ecol., 32(8):1944-1958, August 2018.

37. Kari Koehler, Alyson Center, and Jeannine Cavender-Bares. Evidence for a freezing tolerance-growth rate trade-off in the live oaks (quercus series virentes) across the tropicaltemperate divide. New Phytol., 193(3):730-744, February 2012.

38. Craig Loehle. Height growth rate tradeoffs determine northern and southern range limits for trees. J. Biogeogr., 25(4):735-742, July 1998.

39. Marco A Molina-Montenegro, Jorge Gallardo-Cerda, T S M Flores, and Cristian Atala. The trade-off between cold resistance and growth determines the nothofagus pumilio treeline. Plant Ecol., 213(1):133-142, January 2012.

40. Jessica A Savage and Jeannine Cavender-Bares. Phenological cues drive an apparent trade-off between freezing tolerance and growth in the family salicaceae. Ecology, 94(8): 1708-1717, August 2013.

41. Ying Zhen, Preeti Dhakal, and Mark C Ungerer. Fitness benefits and costs of cold acclimation in arabidopsis thaliana. Am. Nat., 178(1):44-52, July 2011.

42. Ellen Zuther, Elisa Schulz, Liam H Childs, and Dirk K Hincha. Clinal variation in the nonacclimated and cold-acclimated freezing tolerance of arabidopsis thaliana accessions. Plant Cell Environ., 35(10):1860-1878, October 2012.

43. Matthew A Hannah, Dana Wiese, Susanne Freund, Oliver Fiehn, Arnd G Heyer, and Dirk K Hincha. Natural genetic variation of freezing tolerance in arabidopsis. Plant Physiol., 142 (1):98-112, September 2006.

44. Matthew W Horton, Glenda Willems, Eriko Sasaki, Maarten Koornneef, and Magnus Nordborg. The genetic architecture of freezing tolerance varies across the range of arabidopsis thaliana. Plant Cell Environ., 39(11):2570-2579, 2016.

45. Malia A Gehan, Sunchung Park, Sarah J Gilmour, Chuanfu An, Chin-Mei Lee, and Michael F Thomashow. Natural variation in the c-repeat binding factor cold response pathway correlates with local adaptation of arabidopsis ecotypes. Plant J., 84(4):682-693, November 2015.

46. Astrid Junker, Moses M Muraya, Kathleen Weigelt-Fischer, Fernando Arana-Ceballos, Christian Klukas, Albrecht E Melchinger, Rhonda C Meyer, David Riewe, and Thomas Altmann. Optimizing experimental procedures for quantitative evaluation of crop plant performance in high throughput phenotyping systems. Front. Plant Sci., 5:770, 2014.

47. Stephen E Fick and Robert J Hijmans. WorldClim 2: new 1-km spatial resolution climate surfaces for global land areas. Int. J. Climatol., 37(12):4302-4315, October 2017.

48. R Core Team. R: a language and environment for statistical computing, 2017.

49. Envel Kerdaffrec, Danièle L Filiault, Arthur Korte, Eriko Sasaki, Viktoria Nizhynska, Ümit Seren, and Magnus Nordborg. Multiple alleles at a single locus control seed dormancy in swedish arabidopsis. Elife, 5, December 2016.

50. Moises Exposito-Alonso, Claude Becker, Verena J Schuenemann, Ella Reiter, Claudia Setzer, Radka Slovak, Benjamin Brachi, Jörg Hagmann, Dominik G Grimm, Jiahui Chen, Wolfgang Busch, Joy Bergelson, Rob W Ness, Johannes Krause, Hernán A Burbano, and Detlef Weigel. The rate and potential relevance of new mutations in a colonizing plant lineage. PLoS Genet., 14(2):e1007155, February 2018.

51. Rob Patro, Geet Duggal, Michael I Love, Rafael A Irizarry, and Carl Kingsford. Salmon provides fast and bias-aware quantification of transcript expression. Nat. Methods, 14(4): 417-419, April 2017.

52. Xiang Zhou and Matthew Stephens. Genome-wide efficient mixed-model analysis for association studies. Nat. Genet., 44(7):821-824, June 2012. 
bioRxiv preprint doi: https://doi.org/10.1101/2022.02.15.480488; this version posted February 17, 2022. The copyright holder for this preprint (which was not certified by peer review) is the author/funder, who has granted bioRxiv a license to display the preprint in perpetuity. It is made available under aCC-BY 4.0 International license.

${ }_{652}$ Supplemental data 
bioRxiv preprint doi: https://doi.org/10.1101/2022.02.15.480488; this version posted February 17,2022 . The copyright holder for this preprint (which was not certified by peer review) is the author/funder, who has granted bioRxiv a license to display the preprint in perpetuity. It is made available under aCC-BY 4.0 International license.

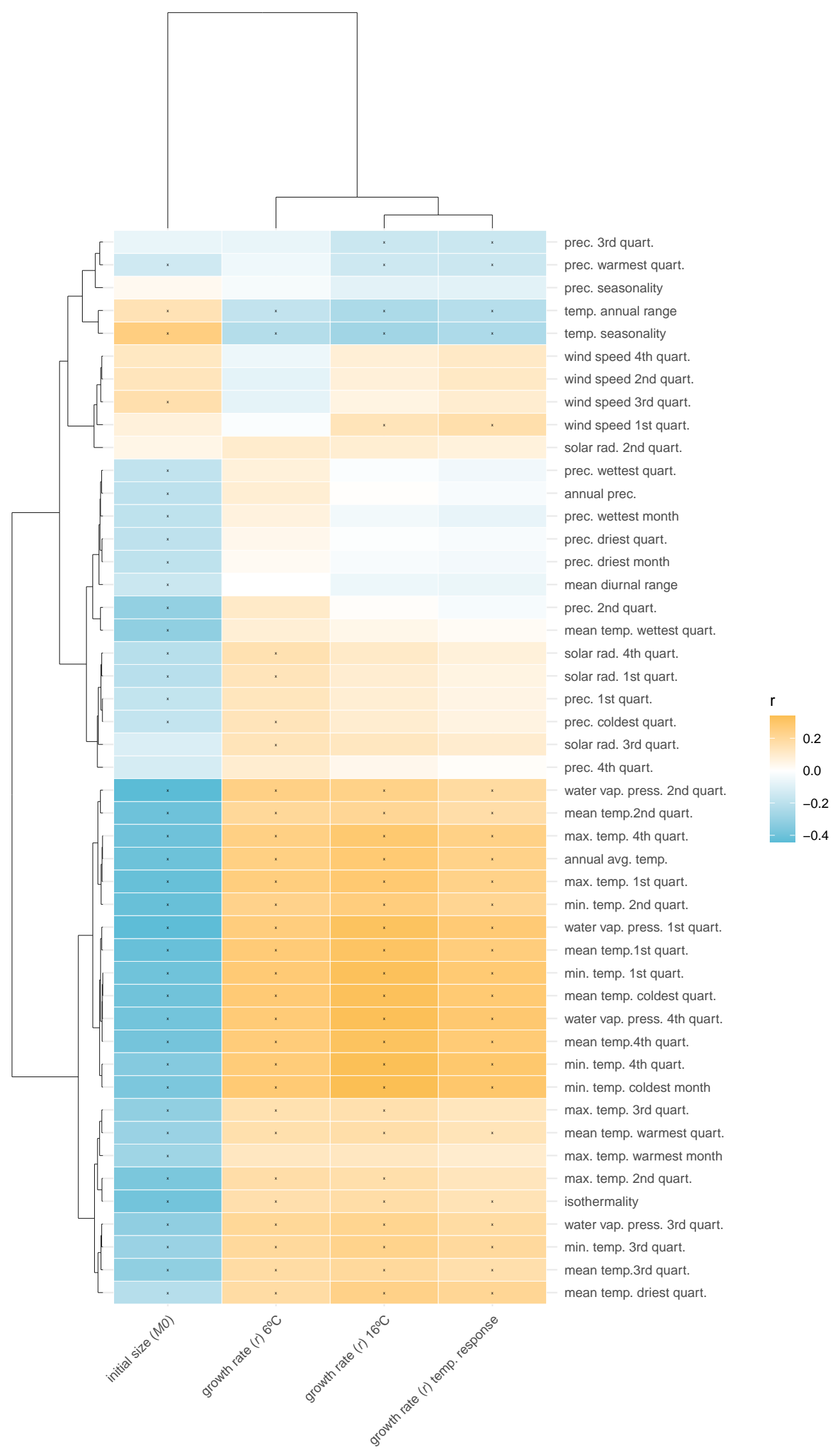

Fig. S1. Correlations between growth parameters and (bio)climate variables. (Bio)climate variables taken from the worldclim database (https://www.worldclim.org). Colors are correlation coefficients, correlations with FDR corrected p-values lower than 0.05 are indicated with a star. The order of the climate variables and phenotypes is based on hierarchical clustering. 
bioRxiv preprint doi: https://doi.org/10.1101/2022.02.15.480488; this version posted February 17,2022 . The copyright holder for this preprint (which was not certified by peer review) is the author/funder, who has granted bioRxiv a license to display the preprint in perpetuity. It is made available under aCC-BY 4.0 International license.

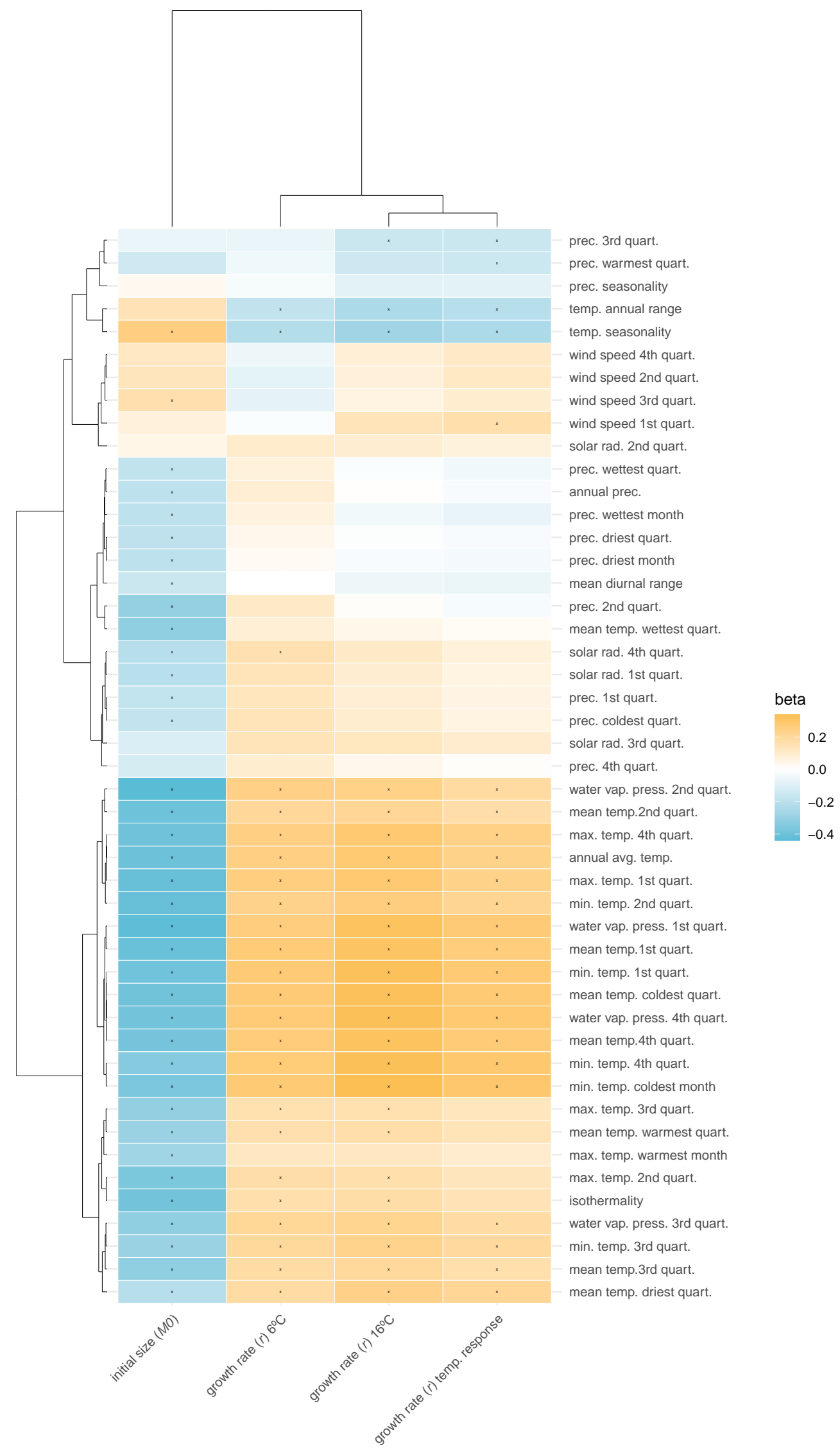

Fig. S2. Population structure corrected correlations between growth parameters and (bio)climate variables. (Bio)climate variables taken from the worldclim database (https://www.worldclim.org). Colors are the coefficients for the climate variable in the mixed model with phenotype as dependent variable and population structure as random factor. Phenotypes and climate variables were standardized, making regression coefficients comparable to correlation coefficients. Correlations with FDR corrected $p$-values lower than 0.05 are indicated with a star. The order of the climate variables and phenotypes is based on hierarchical clustering. 
bioRxiv preprint doi: https://doi.org/10.1101/2022.02.15.480488; this version posted February 17, 2022. The copyright holder for this preprint (which was not certified by peer review) is the author/funder, who has granted bioRxiv a license to display the preprint in perpetuity. It is made available under aCC-BY 4.0 International license.

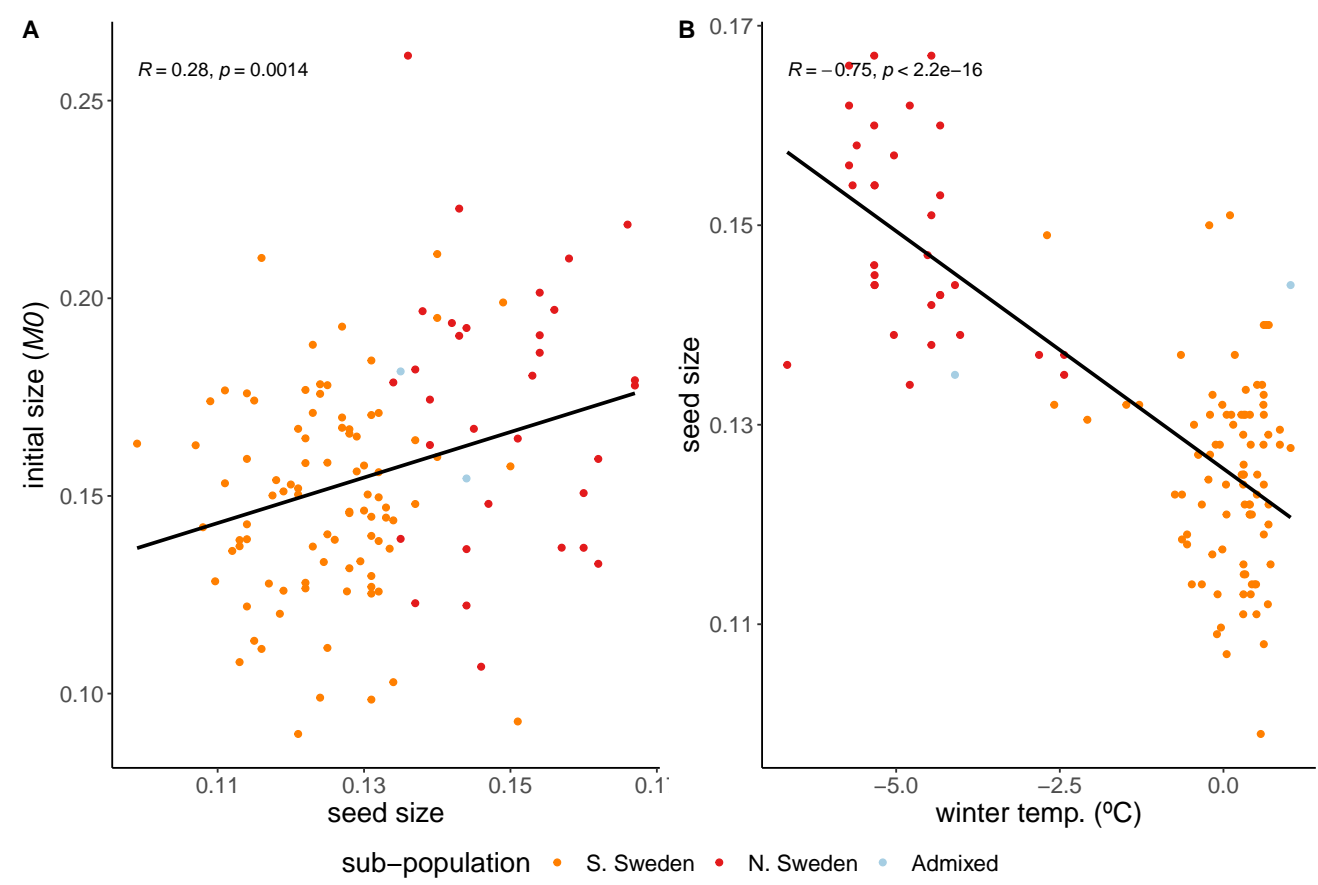

Fig. S3. Correlation between initial size and seed size (A) and between seed size and winter temperature (B) for a subset of 123 Swedish accessions.
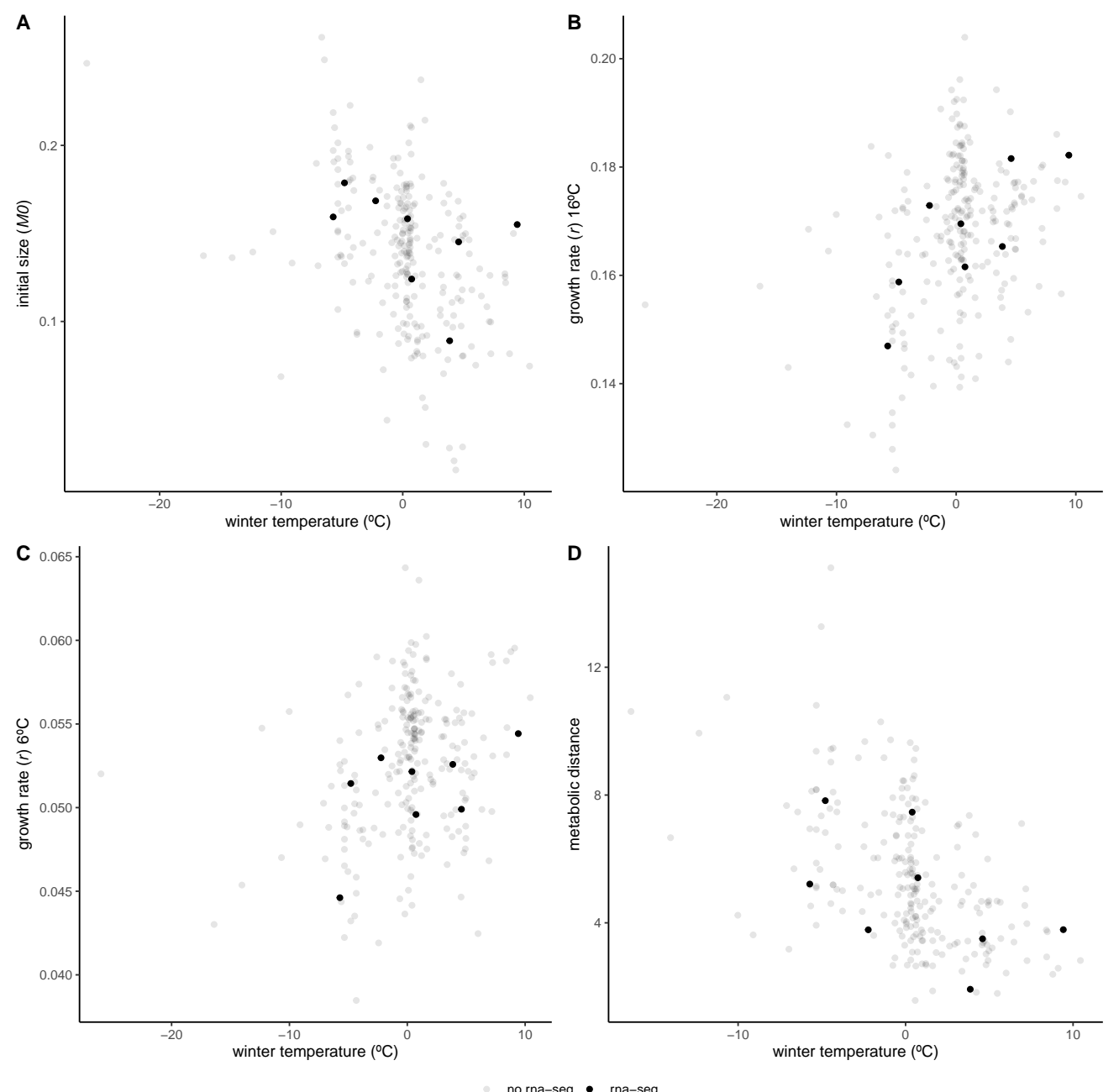

Fig. S4. Growth parameters and metabolic distance of rna-sequenced accessions in relation to local mean temperature of coldest quarter. Initial size (A), growth rate in $16^{\circ} \mathrm{C}$ $(B)$ and $6^{\circ} \mathrm{C}(\mathrm{C})$, and metabolic distance $(\mathrm{D})$, as a measure of temperature response over all 37 measured primary metabolites (21). Accessions selected for RNA-sequencing are depicted in black, remaining accessions are shown in gray. 
bioRxiv preprint doi: https://doi.org/10.1101/2022.02.15.480488; this version posted February 17, 2022. The copyright holder for this preprint (which was not certified by peer review) is the author/funder, who has granted bioRxiv a license to display the preprint in perpetuity. It is made available under aCC-BY 4.0 International license.
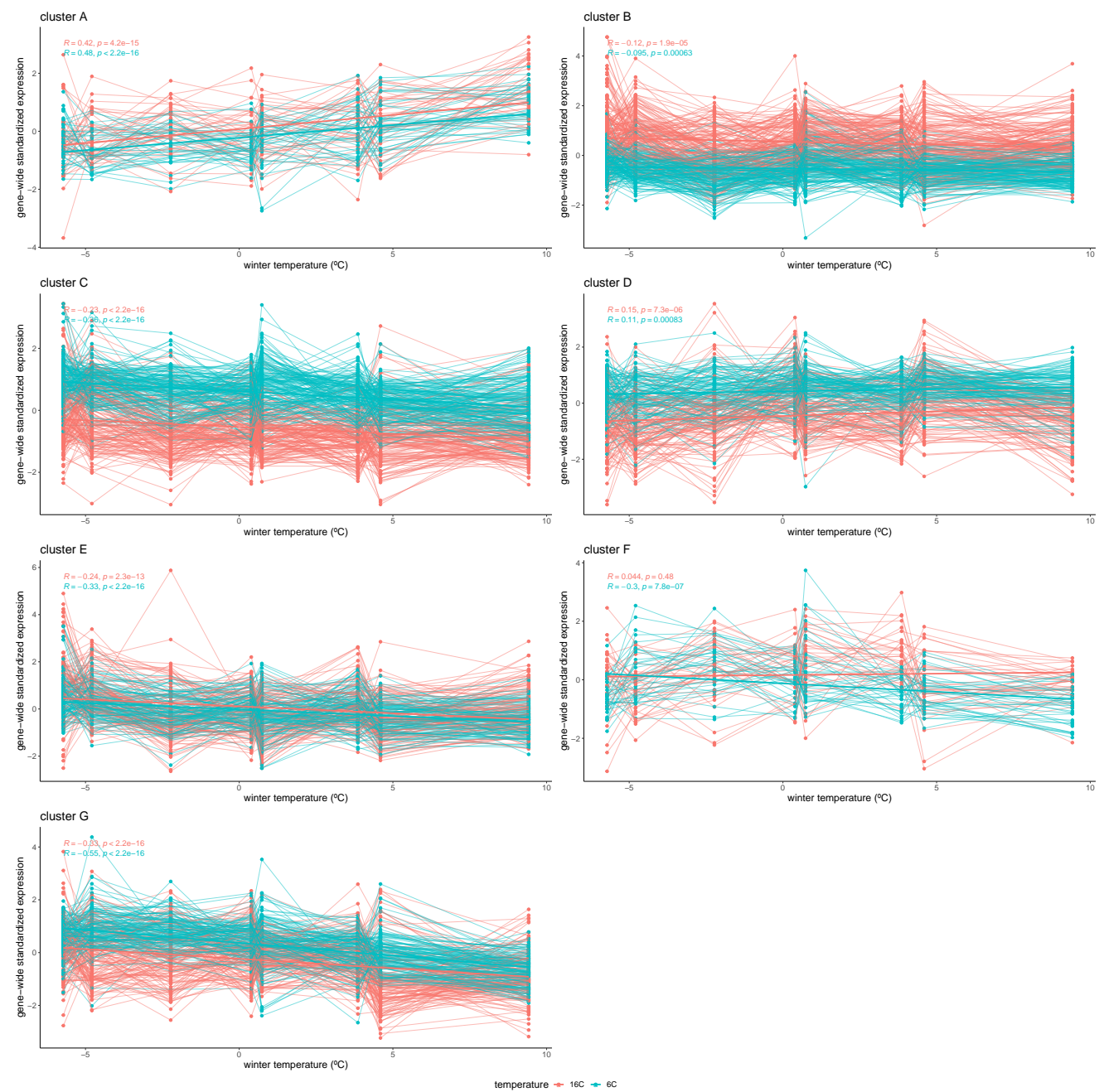

Fig. S5. Cluster-specific expression in relation to winter temperature. Gene-wide standardized expression in $16^{\circ} \mathrm{C}$ (red) and $6^{\circ} \mathrm{C}$ (blue) values are plotted for each gene in clusters 1-7 (A-G), as defined in Figure 5. Expression values of each gene are connected with thin lines. Thick lines represent the correlation of the cluster's expression with the accession's winter temperature. 
bioRxiv preprint doi: https://doi.org/10.1101/2022.02.15.480488; this version posted February 17, 2022. The copyright holder for this preprint (which was not certified by peer review) is the author/funder, who has granted bioRxiv a license to display the preprint in perpetuity. It is made available under aCC-BY 4.0 International license.

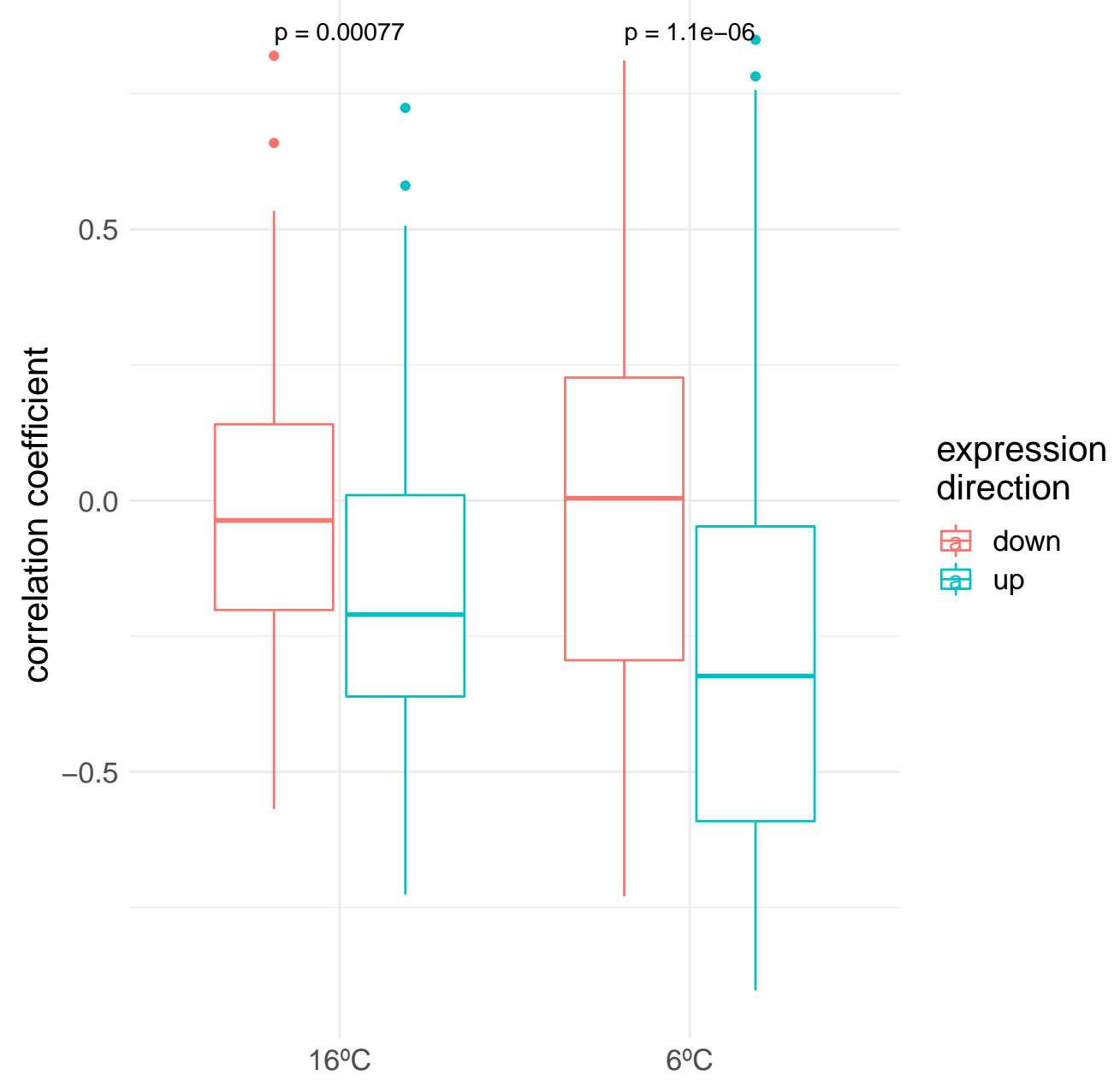

Fig. S6. Gene expression correlations with winter temperature. Correlation coefficients of each gene's correlations with winter temperature are grouped by the experimental temperature $\left(16^{\circ} \mathrm{C}\right.$ and $\left.6^{\circ} \mathrm{C}\right)$ and by the expression direction upon cold exposure as measured by Park et al. and Vogel et al. (22) (23). 
bioRxiv preprint doi: https://doi.org/10.1101/2022.02.15.480488; this version posted February 17, 2022. The copyright holder for this preprint (which was not certified by peer review) is the author/funder, who has granted bioRxiv a license to display the preprint in perpetuity. It is made available under aCC-BY 4.0 International license.

initial size $(M 0)$

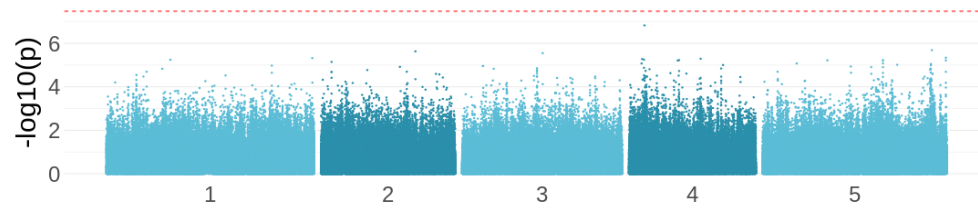

growth rate $(r) 6^{\circ} \mathrm{C}$

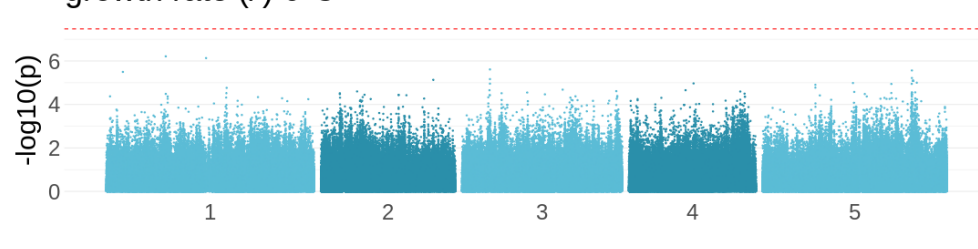

growth rate $(r)$ temp. response

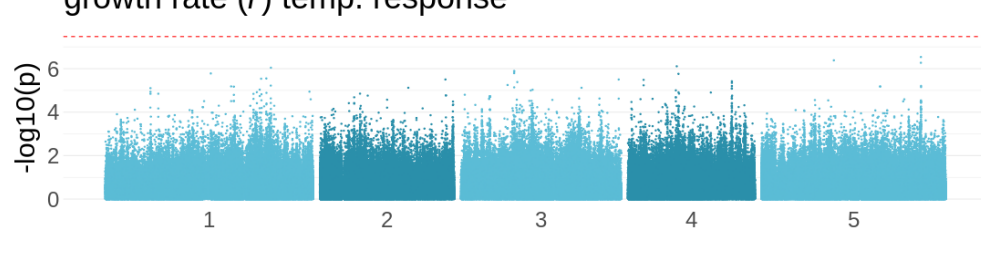

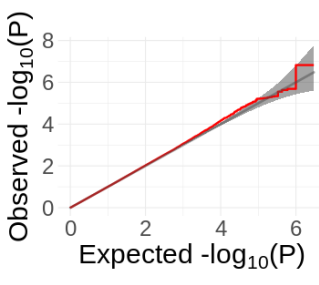
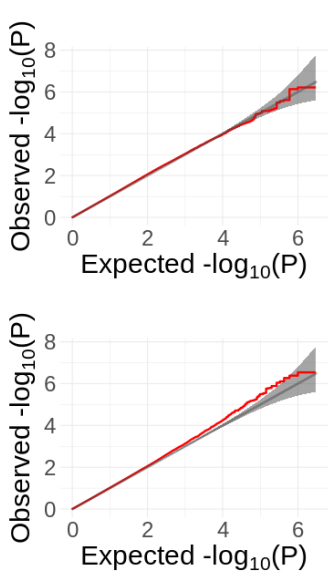

Fig. S7. GWAS results for the initial size, growth rate at $6^{\circ} \mathrm{C}$ and the temperature response of the growth rate. Left: Manhattan plots showing the significance of the association between the initial size, growth rate in $6^{\circ} \mathrm{C}$ and the growth rate's temperature response, and each of the tested SNPs. The bonferroni-corrected threshold is visualized with the dashed red line. Right: QQ-plots showing the relation between observed and expected -log10(p-value) distributions for each of the respective GWAS. Red line shows the observed relationship. Gray line and band show the expected relationship under the null hypothesis of no differentiation between both distributions. 